\title{
CD-ROMs in Academic Libraries: A Survey
}

\section{John M. Budd and Karen A. Williams}

The present study seeks to ascertain the current usage and status of CD-ROM products in academic libraries. The survey asks how many products libraries own or subscribe to, how these are paid for, which titles are held, and how many workstations are supported. Libraries are also asked about usage and cost of CDs. Related areas are also investigated. Questions are asked regarding online search activity and expenditures for the years 1989-1990 and 1984-1985; statistical tests are employed to determine if there has been a significant change in these categories over the time period in question. Finally, libraries are asked if they have canceled print sources as a result of online or $C D$ availability.

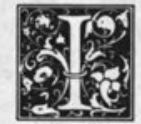

$\mathrm{n}$ the last few years academic libraries have embraced compact disc technology as a means of providing information services to their clientele. Librarians have long recognized the limitations of print sources, such as indexes and abstracts. These print sources are linear in nature, so that a library user has to move forward and backward within or among volumes in order to retrieve information. Users are also, by and large, limited to searching only one descriptor or index term at a time. Over the last few years online access to databases has provided librarians and users with greater search flexibility. However, the pricing structure of many of the available databases and the budgetary vagaries of trying to reconcile anticipated use and possible costs have proved to be obstacles to the use of online services. Expansion of CDROMs as information storage and retrieval mechanisms has presented another option for providing services in libraries. The number of available products has grown as the library market has demon- strated a willingness to adopt them as acquisitions and subscriptions.

As CDs entered libraries, articles on the organization and management of services based on the medium began to appear.' Harter and Jackson attempted to pinpoint the major issues surrounding any optical disc system in a library:

- databases

- search system characteristics

- end-user searching and effectiveness

- education and training

- staffing

- costs

- funding ${ }^{2}$

There is evidence of an awareness that CD-ROM has significantly changed the way in which library users access information. Patrons have quickly and enthusiastically adopted the technology as an exciting alternative to print and online, appreciating the convenience, ease of use, and greater degree of control over the search process that the medium offers. ${ }^{3}$

User affinity for the product is borne out to some extent by a survey conducted at

John M. Budd is at the School of Library \& Informational Science, University of Missouri-Columbia, Columbia, Missouri 65211. Karen A. Williams is Team Leader for the Social Science Team, University of Arizona, Tucson, Arizona 85721. 


\section{Columbia University. Juhl and Lowry} report:

In Butler Reference, 34 percent of our respondents found that a specific CD-ROM product was essential to their research, 75 percent found the CD-ROM version of an index easier to use than its printed counterpart, and 71 percent preferred the $C D-R O M$ format to paper. ${ }^{4}$

Probably the most important issue for librarians is the cost of CDs. Since CDs do not constitute a service with costs as widely variable as online databases, they usually are not treated in the same manner as online services are handled. At the same time, they frequently are not treated exactly in the way print sources are, because of the accompanying hardware considerations. Additionally, maintaining printers for public use means costs for paper and related supplies. Another concern Johnson points out is that there is the likelihood of necessary duplication of $\mathrm{CD}$ and print sources, at least in the short term. ${ }^{5}$ This puts added pressure on already stretched library budgets. Perhaps because of the limitations on organizational budgets there exists what Beltran perceives as the fear "that increased support for automated information sources is likely to come from funds supporting disciplines in which automated systems are less available and important.". pressure has resulted in a cooperative effort such as that in Pennsylvania, where PALINET has assisted libraries in obtaining both hardware and the $C D$ products themselves at discounted prices for member libraries. ${ }^{7}$ The phenomena of increased use and demand and concomitant costs present a dilemma for libraries and, at present, there is a dearth of data on both activity and funding options. Despite the paucity of information, there is considerable interest in the subject, as indicated by exchanges via electronic mail and electronic bulletin boards.

\section{THE PRESENT SURVEY}

The above issues relating to acquisitions of $\mathrm{CD}$ products and financing the products and services form the focus of a survey of academic libraries, con- ducted in 1991. The purpose of the survey is to gather data on libraries' applications of CDs in their informational services. In addition, the survey seeks to determine what has happened with online search activities and expenditures over the last several years and whether online and $C D$ services have affected the holdings of print sources. The questions are designed to ascertain the extent of libraries' holding of $\mathrm{CD}$ products and what sources are commonly held by the libraries. They also ask about expenditures on these products and where the funds come from for purchase or subscription. Most of the data requested is from the 1989-1990 fiscal year. Where comparative information of any sort is sought, questions are based on the 19841985 year as well. ${ }^{8}$

Probably the most important issue for librarians is the cost of CDs.

The authors decided that the population of academic libraries would have to be limited, since resources precluded surveying all libraries. Also, since CDROM products and related equipment require substantial financial commitment by libraries, only those libraries with budgets large enough to accommodate the medium would be included. Fortunately, there are sets of institutions which fit this criterion and assure representation from a wide geographic area and from both public and private schools. The population surveyed was comprised of the members of the Association of Research Libraries and the ACRL University Libraries (as determined by the Association of College and Research Libraries). In order to avoid problems of overall governance, availability of products, and currency exchange rates, only United States libraries were surveyed. Additionally, only those libraries with total materials expenditures of at least $\$ 500,000$ were included. This resulted in a survey of 180 libraries. A total of 113 libraries (62.7 percent) returned questionnaires with at least some 
of the questions answered. Local data collection did not allow for response to every question by every library returning the questionnaire.

The survey is designed to yield primarily descriptive results, since there is very little baseline data with which to compare responses. For this reason, the survey questions themselves form the research questions underlying this study, for the most part. Where comparative information is requested, there is the possibility for some hypothesis testing. The working hypotheses are that the difference between 1984-1985 data and 19891990 data is statistically significant $(p<$ .05 ) with regard to changes in numbers of mediated online searches and expenditures on those searches. These will be tested as null hypotheses. The survey is also limited to the "academic" libraries on each campus; that is, it excludes law and medical (or health sciences) libraries. The reason for this limitation is that some of these libraries are in locations remote from the main campuses and many of the law and medical libraries are administratively separate from the academic library systems.

\section{FINDINGS}

Libraries reporting data relevant to this study cannot provide information regarding every question, due to some vagaries of local record keeping. This in itself indicates a potential problem area in library management. At times libraries have a tendency to make decisions about costly products and services with inadequate information. The first survey question begins with the most basic information-the number of products to which the library subscribes. A total of 112 libraries responded to this question and the mean response is 19.1 products. The next question focuses on the number of workstations in each library. The mean for the 110 responding libraries is 14.1 workstations.

The third question asks, specifically, to which indexing and abstracting products libraries subscribe. Some choices are made available on the questionnaire, along with space provided for respondents to in-
TABLE 1

TEN MOST FREQUENTLY

SUBSCRIBED TO INDEXING AND ABSTRACTING PRODUCTS

\begin{tabular}{ll}
\hline Title & No. \\
\hline PsychLit & 96 \\
ERIC & 92 \\
ABI/Inform & 74 \\
MLA Bibliography & 62 \\
GPO's File & 56 \\
Medline (in academic libraries & \\
only) & 56 \\
Dissertation Abstracts Ondisc & 46 \\
Sociofile & 45 \\
Infotrac & 40 \\
Agricola & 34 \\
\hline
\end{tabular}

clude additional products. Responding libraries offer a considerable variety of titles; in fact, 104 unique titles receive at least one mention each. Some titles are quite widely held; the ten most frequently used products are listed in table 1 .

The list holds few, if any, surprise for reference librarians. The CD titles listed represent areas of traditional information needs in academic libraries.

\section{At times libraries have a tendency to make decisions about costly products and services with inadequate information.}

Next, libraries are asked how the indexing and abstracting titles are firanced. The choice of responses includes the mention of alternatives available locally. A total of seventy-four libraries indicates that the serials budget is the source of financing CD-ROMs. The second most frequently occurring source of funding is the reference budget, so noted by twenty-eight libraries. The following sources also provide financing, with the number of responding libraries in parentheses: monographic budget (13), separate CD budget (11), automation budget (8), grants (3), special funds (3), gift money (2), general materials budget (1), one-time legislative appropriation (1), and online search budget (1). 
Eighty-eight libraries are also able to provide information on how much is spent each year on indexing and abstracting titles. On average, these libraries spend $\$ 36,550$. The next question seeks to determine the number of uses of these indexing and abstracting products in 1989-1990. Only thirty-five libraries were able to respond to this question. The mean number of patron uses for these responding libraries is 15,988 . While few libraries maintain data on usage (and accurate counts of uses, even when sign-up sheets are used and monitoring is attempted, is very difficult), the responses to these two questions invite calculation of average cost per use. If the average amount spent on the products is divided by the average number of uses, the result is $\$ 2.29$ per use. One library offers its estimate of cost per use; it figures that CD-ROM searches cost about 75 cents each, while the cost for other automated resources is $\$ 13.80$ per search. These figures, which may not be a usable representation of cost per use, are deceptive. There are other costs attached to the use of CD-ROMs, such as hardware expenditures (even if amortized), paper and other supplies, and possibly the librarian's time to assist users. Future research on the reference process may focus on sampling the use of CDs and print sources in an attempt to discover cost-per-use comparisons.

Indexing and abstracting titles are not the only products libraries subscribed to or purchased. The next question asks to which nonbibliographic sources on CDROM libraries subscribe. Again, some choices are provided to respondents, but they are free to add any other titles they receive. There are even more nonbibliographic titles in libraries' repertoires than indexing and abstracting titles. Libraries report holding 136 unique titles; further, there is greater dispersion of holdings, with fewer titles being widely held by libraries. The most frequently subscribed to source is Compact Disclosure, held by forty-three libraries. The next four titles in order of frequency of subscription are: BIP Plus (31 libraries), Oxford English Dictionary (23), Academic
American Encyclopedia (18), and Ulrich's Plus (15). The number of titles held by libraries is likely to increase in the near future; government document depository libraries expect more and more government information to be produced on CD-ROM.

The libraries were asked how the nonbibliographic products are funded. The four most frequently mentioned sources are identical to the sources of financing noted for indexing and abstracting titles, though the order is slightly different. Other, less frequently occurring sources vary a bit from the above. The list of sources is as follows, with the number appearing in parentheses: serials budget (32), monographic budget (28), reference budget (22), separate CD budget (7), endowment funds (3), automation budget (3), gift money (2), special materials budget (1), media budget (1), soft money (1), and teaching materials budget (1). The primary difference between funding sources for these types of $C D$ products and the indexing and abstracting titles is the number reporting the monographic budget; nonbibliographic products are less frequently classified as serials.

\section{Future research will have to address the trade-offs when libraries opt for one storage and retrieval medium over another.}

Related to the purpose of this study is the examination of online search activity both during the survey period and in the recent past. Eighty-seven libraries offer information on the number of mediated searches in 1989-90. The mean number of searches for the libraries is 1,698 . This figure is deceptive, however, since one reporting library states that 70,172 searches were performed in that year. If data are smoothed and this response is ignored, the mean for the remaining eighty-six libraries is 902 . For the year 1984-1985 the seventy-six responding libraries yield a mean number of searches of 1,320 . One library mentions that the number of mediated searches in the sciences is masking the 
TABLE 2

MOST FREQUENTLY CANCELED PRINT TITLES DUE TO CD-ROM AVAILABILITY

\begin{tabular}{ll}
\hline Title & \multicolumn{1}{c}{ No. } \\
\hline Dissertation Abstracts & 7 (1 duplicate subscription) \\
RIE & 6 (2 duplicate subscriptions) \\
Bibliography of Agriculture & 5 (1 duplicate subscription) \\
Business Periodicals Index & 5 (3 duplicate subscriptions) \\
CIJE & 5 (1 duplicate subscription) \\
Reader's Guide & 5 (4 duplicate subscriptions) \\
Science Citation Index & 5 (3 duplicate subscriptions) \\
Sociological Abstracts & 5 (no duplicate subscriptions) \\
Books in Print & 4 (1 duplicate subscription) \\
Psychological Abstracts & 4 (all duplicate subscriptions) \\
\hline
\end{tabular}

drop in the social sciences during the time period. Another, which is not able to provide data for both years, indicates that the number fell from 499 in 19871988 to zero in 1989-1990. A total of seventy libraries report expenditures for $1989-1990$; the mean amount is $\$ 18,534$. The mean for the fifty-four libraries indicating 1984-1985 expenditures is $\$ 23,656$.

While it is not possible to assign a direct causal link to the rise of CDs in libraries and changes in mediated online searching, there well may be a coincidental relationship. The working hypotheses regarding numbers of searches and expenditures on mediated searches are stated above. The null hypotheses are that there is no statistically significant difference $(p<.05)$ between the number of searches in 1989-1990 and that in 1984-1985, and between amount expended in 1989-1990 and that in 19841985. In order to test these hypotheses, the $t$-test is employed. Since there is a population of libraries reporting comparable data for the two years in question, a paired $t$-test (that is, one which matches the responses for the two years for each library) presents a more accurate indication of comparison. Seventytwo libraries report data regarding the number of mediated searches conducted for both years. The computed $t$ value ( $d f$ $=70$ ) is 8.79 ; therefore the null hypothe- sis is rejected at $p<.05$. (Actually, in this instance the hypothesis can be rejected at $p<.001$.) Only sixteen libraries report conducting more searches in 1989-1990 than in 1984-1985; one reports an identical number. The paired $t$-test can also be used to test the null hypothesis with regard to expenditures. Fifty-four libraries respond with data for both years. The computed $t$ value $(d f=52)$ is 2.52 , so the null hypothesis is rejected once again at p.05. Of the fifty-four libraries reporting comparable data for both years, eighteen indicate that they spent more in 19891990 than in 1984-1985. If constant dollars were used (that is, if figures were not corrected for inflation), the difference in the time period would be even greater.

The remaining questions inquire about print sources canceled as a result of online access or CD-ROM purchase. A total of 107 libraries respond concerning the effect on print titles of availability of online databases. Thirty-four libraries indicate that in recent years they have canceled seventy-three subscriptions of fifty-four unique titles (many of the cancellations being of duplicate subscriptions). The cancellations due to online availability are quite diffuse. The title mentioned most frequently is Chemical Abstracts, with seven subscriptions canceled-six of those were either duplicate or incomplete subscriptions. Psychological Abstracts was the target of three cancellations, all of them 
duplicate subscriptions. Three libraries also canceled Exerpta Medica; none of these was a duplicate.

More subscriptions (104) to slightly fewer unique titles (50) were canceled because of the availability of CD-ROM products. The ten most frequently mentioned titles are listed in table 2.

Some libraries also volunteer that five print sources were canceled because of the inclusion of some files in their online public access catalogs (OPACs). One library notes that it had canceled both print and $\mathrm{CD}$ subscriptions when databases were added to its OPAC. Several libraries note that titles are being considered for cancellation because of CD or online availability and one said that it has opted not to buy some print sources in the first place because of alternative media. One respondent states, "We have a standard policy of canceling print versions whenever the CD-ROM is added to the network. We have received no resistance. We are experiencing great pressure to acquire as many CD-ROMs as possible." A recent study of the relationship between print subscriptions and online availability at colleges and universities with fewer than 10,000 students was conducted by Wall, Haney, and Griffin. ${ }^{9}$ They find that online availability is an influencing factor in libraries' decisions to retain or cancel print subscriptions.

\section{SUMMARY}

As noted, the aim of this study is to present some benchmark data on CDROMs in academic libraries so that future comparisons may be made. Toward that end, descriptive data are presented regarding numbers of products purchased or subscribed to, numbers of workstations available, expenditures on products, and specific titles held. The findings detail the responses of libraries to the survey sent them. It is evident from these responses that CDs have found a place in libraries. Responses to questions on both usage and expenditures indicate that libraries are commit- ting resources to the products and that they are being used at a rate that may well render them a cost-effective means of providing information to the library's users. The number of different titles of products mentioned by respondents shows that libraries are employing the medium to provide information in a wide diversity of areas.

The results of this survey also display the decline of online searching activity in libraries in recent years. The drops in both number of searches and amount expended on the service are statistically significant. Further study of these phenomena may seek to determine how online access will be used in academic libraries in the future and which subject areas will be affected most. Charles and Clark present one strategy for the use of online databases-updating CD-ROM searches with online availability. ${ }^{10}$ One outcome of such an investigation may be the formulation of a model that can be employed by libraries to predict future expenditures for online services, so that budgetary decisions may be simplified.

Additionally, some libraries are taking long looks at their holdings in other media, especially print, and choosing to make some cancellations. Given the reality of financial constraints faced by libraries, the need to make the best use of funding is evident. Future research will have to address the trade-offs when libraries opt for one storage and retrieval medium over another. Questions library staff must consider involve cost to the users, ancillary costs to the library (such as hardware and supplies), retrieval flexibility, and space. This study presents some data that individual libraries can use to assess the activities of their own operations and that libraries in general can employ in conducting longitudinal studies in the future. The breadth of this study should allow for these comparisons and should provide an indication of the current state of CDROMs in libraries. 


\section{REFERENCES AND NOTES}

1. Kathy M. Jackson, Evelyn M. King, and Jean Kellough, "How to Organize an Extensive Laserdisk Installation: The Texas A\&M Experience," Online 12 (Mar. 1988): 51-60; and Sandra L. Tucker, Vicki Anders, Katharine E. Clark, and William R. Kinyon, "How to Manage an Extensive Laserdisk Installation: The Texas A\&M Experience," Online 12 (May 1988): 34-46.

2. Stephen P. Harter and Susan M. Jackson, "Optical Disc Systems in Libraries: Problems and Issues," RQ 27 (Summer 1988): 517-18.

3. Joseph A. Michalak, "Observations on the Use of CD-ROM in Academic Libraries," Serials Librarian 17, nos. $3 / 4$ (1990): 63.

4. Beth Juhl and Anita Lowry, "The CD-ROM'Revolution' at Columbia: Year One," Serials Librarian 17, nos. 3/4 (1990): 71-72.

5. Peggy Johnson, "Dollars and Sense," Technicalities 9 (Mar. 1989): 7.

6. Ann Bristow Beltran, "Funding Computer-Assisted Reference in Academic Research Libraries," Journal of Academic Librarianship 13 (Mar. 1987): 7.

7. Karen Sandlin Silverman, "CD-ROM in Libraries: Access, Trends and Challenges," Serials Librarian 17, nos. 3/4 (1990): 52.

8. The survey instrument is available from the authors. Anyone wishing to obtain a copy should contact John M. Budd at the School of Library \& Informational Science, University of Missouri-Columbia, Columbia, Missouri 65211.

9. Celia Wall, Roger Haney, and John Griffin, "Hard Copy versus Online Services: Results of a Survey," College \& Research Libraries 51(May 1990): 267-76.

10. Susan K. Charles and Katharine E. Clark, "Enhancing CD-ROM Searches with Online Updates: An Examination of End-User Needs, Strategies, and Problems," College \& Research Libraries 51 (July 1990): 321-28. 


\title{
ASSOCIATION OF COLLEGE RESEARCH LIBRARIES \\ OVER 10,000 PROFESSIONALS
}

\author{
SHARING IDEAS
}

PROVIDING OPPORTUNITIES

FINDING SOLUTIONS

$\nabla$ Build your professional skills and expertise through more than 100 educational programs held each year. Experience the challenging programs offered at the ACRL National Conference, the ALA Annual Conference, preconferences, and local continuing education courses.

$\nabla$ Benefit from valuable research and practical ideas by reading ACRL's varied publications-College \& Research Libraries, College \& Research Libraries News, Choice, Rare Books \& Manuscripts Librarianship, Books for College Libraries, CLIP Notes.

$\nabla$ Connect with colleagues from around the state, country, and around the world.

\section{BECOME A PART OF SOMETHING GREAT- JOIN TODAY!}

Association Of C O L LEGE \& RESEARCH LIBRARIES AMERICAN LIBRARY ASSOCIATION
Get your membership information by calling $800-545-2433$, ext. 2517 , by faxing this form to $312-280-2520$, or by sending this form to ACRL, $50 \mathrm{E}$. Huron St., Chicago, IL 60611.

Name

Address

City

State

Zip 